\title{
Lowering Carbon Foot Print of Portland Cement by Class F Fly Ash Replacement in Mortar Mixture in Terms of Workability and Strength Properties
}

\author{
Asadullah Zaki ${ }^{1 *}$, Cengiz Duran Atiş ${ }^{2}$ iD \\ ${ }^{I}$ Istanbul University-Cerrahpasa, Faculty of Engineering , Department of Civil Engineering, Istanbul, \\ Turkey. \\ ${ }^{2}$ Erciyes University, Faculty of Engineering, Department of Civil Engineering, Kayseri, Turkey. \\ *asadullah.zaki@ogr.iu.edu.tr
}

\begin{abstract}
In the experimental work, recycling by inclusion of class $\mathrm{F}$ fly ash in mortar was investigated in terms of workability and strength of mortar to fabricate an environment friendly construction material. For this aim, class $\mathrm{F}$ fly ash were used as cement replacement at $10 \%, 30 \%, 50 \%$ and $70 \%$ ratios in mortar. Waterbinder ratios were $0.40,0.45$ and 0.50 . A total of 15 different mortar mixtures including control Portland cement and fly ash mortar were produced. Workability of fresh mortar was measured using mini flow testing. Flexural and compressive strength of hardened standard sized samples were measured after completion of their specified curing time at $1 \mathrm{~d}, 3 \mathrm{~d}, 7 \mathrm{~d} 28 \mathrm{~d}, 3 \mathrm{~m}$ and $6 \mathrm{~m}$. Experimental results showed that inclusion of fly ash in mortar improved workability with respect to control Portland cement mortar. Recycling low amount of fly ash in mortar did not show detrimental but beneficial influence on strength properties of mortar. However, employing high amount of fly ash in mortar reduced flexural and compressive strength at early ages, however, the reduction in flexural and compressive strengths were remedied due to pozzolanic reaction of fly ash at longer curing time compared to control Portland cement mortar. It was concluded that current fly ash was a suitable pozzolanic material to be recycled by replacement with Portland cement in mortar to manufacture clean construction material in terms of workability and strength concern.
\end{abstract}

Keywords: Mortar, Fly ash, Workability, Strength

\section{INTRODUCTION}

Fly ashes are residue of electric power station that consumes pulverised lignite or sub-bituminous coal and they are in powdered form. It is called class $\mathrm{F}$ fly ash if it is originated from sub-bituminous coal and contains low amount of lime less than $10 \%$. It is called class $\mathrm{C}$ fly ash if it is originated from lignite coal and contains high amount of lime higher than 10\%. Managing storage and disposal of fly ashes are an environmental concern. It is known that some fly ashes own pozzolanic property, and they can be utilized in mortar or concrete as partial replacement of Portland cement. Sometimes it can be introduced in mortar or concrete mixture as partial replacement of sand. Employing fly ash in cement based mixtures as partial 
replacement of cement provides saving from the amount of cement used in the mixtures as well as help to solve waste management and disposal issue of fly ash [1-6].

When a proper fly ash was employed in production of mortar or concrete, it modifies many properties of mixtures made with. For instance, its usage improves workability, reduces bleeding and segregation in fresh state of mortar or concrete mixtures. Fly ash inclusion also influences hardened properties of mixtures. For example, while it tends to reduce early strength properties of mixtures, it contributes to strength properties of hardened mortar or concrete in favour [6-10].

On the other hand, production of cement consumes natural sources and increases carbon-dioxide emission to atmosphere, which is considered as detrimental to natural environment. Production of cement was hold responsible for $10 \%$ of total carbon dioxide emission to atmosphere, due to usage of calcareous matter and calcination energy used in the production of Portland cement. Disintegration of calcareous matter also results with carbon-dioxide emission [11, 12].

Employing fly ash in mortar or concrete as a substitution of cement helps to disposal of fly ash and it reduces amount of cement consumption for a cubic meter of mortar or concrete production. It reduces needs for cement amount for a cubic meter of cement based mixtures, thus, reduces carbon-dioxide emission [2, $13,14]$.

In this experimental study, a class $\mathrm{F}$ fly ash obtained from an electric power station consuming subbituminous pulverised coal was employed as partial substitution of Portland cement in mortar. Investigation of using fly ash in mortar to lower the carbon footprint of Portland cement was carried out in terms of workability of mortar in fresh state and flexural and compressive strength properties of hardened mortar. Fly ash mortar mixtures were prepared for different partial replacement ratios as well as for different waterbinder ratios to realize this aim. Control reference mortar mixtures were also prepared for comparison purposes. Workability testing measurements were carried out while mortar mixtures prepared was in fresh state. Flexural and compressive strength measurements were carried out on mortar mixtures in hardened state at specified curing age. Experimental results were evaluated.

\section{EXPERIMENTAL PROGRAM AND MATERIALS USED}

In the experimental work, Portland cement was used as the main binder, it is Type I cement for general use and it was named as PC42.5R type. Class F type fly ash was used as secondary binder with cement, and it was obtained from electricity generating Sugözü thermal power plant located in Yumurtalık ounty of Adana city of south Turkey. Chemical ingredients of cement and fly ash as oxide compositions were presented in Table 1. Standard RILEM Cembureau sand complied with TS EN 196-1 [15], sand was used in preparation of mortar. Three different control Portland cement mortar mixtures were prepared for three water-binder ratios, $0.40,0.45,0.50$ values. Sand-cement ratio was 3 for each mortar mixture. Water used was supplied from drinkable city tap water. Control mortar mixtures were then modified by replacing cement with fly ash. Therefore, fly ash mortar mixtures were obtained for different fly ash replacement ratios as partial replacement of fly ash with cement. The replacement ratios of fly ash were 10\%, 30\%, 50 and $70 \%$ in mass basis. Using above mixture parameter, three water-binder ratios and four fly ash replacement ratio including control Portland cement mortars and mortar containing fly ash, a total of 15 different mortar mixtures were obtained and prepared. Workability of all mortar mixtures prepared were measured using mini flow workability specified and defined by ASTM C 230 [16]. Mix proportions maintained for three cell mould with 40x40x160 mm dimensions were presented in Table 2. Three cell moulds were filled with fresh mortar mixtures in accordance with relevant standard, TS EN 196-1 [16]. After filling fresh mortar mixtures in three cell mould, specimens covered with wet burlap were left in laboratory condition for a day to set. After a day, hardened specimens were taken out of their mould. Some specimens were subjected to flexural and compressive strength testing to measure at one day strength. Other specimens were stored in a moist environment at $20^{\circ} \mathrm{C}$ temperature, until flexural and compressive strength testing days. After completing curing time, flexural and compressive strengths were measured for each specific curing time. While flexural strength results were average of three prismatic specimens, compressive strength results were average of 
six specimens obtained from ends of halved broken pieces of prismatic specimens provided after flexural testing of prisms specimen.

Table 1. Oxide composition of cement and fly ash (\%)

\begin{tabular}{|c|c|c|c|c|c|c|c|c|c|}
\hline Oxide & $\mathrm{SiO}_{2}$ & $\mathrm{Al}_{2} \mathrm{O}_{3}$ & $\mathrm{Fe}_{2} \mathrm{O}_{3}$ & $\mathrm{CaO}$ & $\mathrm{SO}_{3}$ & $\begin{array}{c}\mathrm{Na}_{2} \\
\mathrm{O}\end{array}$ & $\mathrm{K}_{2} \mathrm{O}$ & $\mathrm{MgO}$ & LOI \\
\hline $\begin{array}{c}\mathrm{PC} \\
42,5 \mathrm{R}\end{array}$ & 18.69 & 5.61 & 2.54 & 62.68 & 2.73 & 0.13 & 0.77 & 2.63 & 1.8 \\
\hline $\mathrm{FA}$ & 61.81 & 19.54 & 7.01 & 1.77 & 0.31 & 2.43 & 0.99 & 2.56 & 2.2 \\
\hline
\end{tabular}

Table 2. Mixture proportions (gr)

\begin{tabular}{|c|c|c|c|c|c|}
\hline R. ratio(\%) & w/b (\%) & Sand & Cement & Fly Ash & Water \\
\hline 0 & 50 & 1350 & 450 & 0 & 225.0 \\
\hline 0 & 45 & 1350 & 450 & 0 & 202.5 \\
\hline 0 & 40 & 1350 & 450 & 0 & 180.0 \\
\hline 10 & 50 & 1350 & 405 & 45 & 225.0 \\
\hline 10 & 45 & 1350 & 405 & 45 & 202.5 \\
\hline 10 & 40 & 1350 & 405 & 45 & 180.0 \\
\hline 30 & 50 & 1350 & 315 & 135 & 225.0 \\
\hline 30 & 45 & 1350 & 315 & 135 & 202.5 \\
\hline 30 & 40 & 1350 & 315 & 135 & 180.0 \\
\hline 50 & 50 & 1350 & 225 & 225 & 225.0 \\
\hline 50 & 45 & 1350 & 225 & 225 & 202.5 \\
\hline 50 & 40 & 1350 & 225 & 225 & 180.0 \\
\hline 70 & 50 & 1350 & 135 & 315 & 225.0 \\
\hline 70 & 45 & 1350 & 135 & 315 & 202.5 \\
\hline 70 & 40 & 1350 & 135 & 315 & 180.0 \\
\hline
\end{tabular}

\section{RESULTS AND DISCUSSION}

\subsection{Workability Results}

Workability testing results of mortars made with different fly ash replacement ratios and water-binder ratios were presented in Table 3. Close evaluation of Table 3 indicated that incorporating fly ash in mortar mixture improved workability of mortar; moreover, increment in replacement ratio of fly ash with cement caused further improvement in workability. This finding of betterment in workability was found to be valid for each water-binder ratios. Whilst water-binder ratio increases, it was observed that workability values of mortar enhanced. This betterment influence of fly ash on workability of mortar was enhanced more with the increase in water-binder ratio. With the increase in water-binder ratio in mixture, the synergy between water and fly ash boost workability of mortar more.

Three reasons were made responsible to explain the improvement in workability by inclusion of fly ash in mortar. First reason is that, fly ash is replaced with cement in mass basis, therefore, differences between densities of fly ash and cement causes an increase in volume of powdered materials in mortar, which means more binder paste volume employed in workability of mortar. Second reason is that, fly ash particles own spherical structure, thus, particles with spherical shape contacts to each other or other solid particles at one point causing minimal interaction between them, which reduces friction forces by ball-bearing effect. Therefore, low friction between solid particles results with an enhancement in workability of mixture. Thirdly, fly ash particles own amorphous-glassy structures with low water absorption capacity. Low water absorption capacity of fly ash particles means less amount of water to be absorbed and rest of mixing water was to be used in workability of mixtures.

Table 3. Workability of mortars (mm)

\begin{tabular}{|c|c|c|c|}
\hline Replacement $(\%)$ & $\mathrm{w} / \mathrm{b}=0,40$ & $\mathrm{w} / \mathrm{b}=0,45$ & $\mathrm{w} / \mathrm{b}=0,50$ \\
\hline 0 & 110 & 130 & 160 \\
\hline 10 & 110 & 140 & 175 \\
\hline
\end{tabular}




\begin{tabular}{|l|l|l|l|}
\hline 30 & 115 & 150 & 190 \\
\hline 50 & 140 & 160 & 200 \\
\hline 70 & 140 & 170 & 210 \\
\hline
\end{tabular}

\subsection{Compressive Strength Results}

Compressive strengths of samples produced in the laboratory work were measured after completion of their curing time. Compressive strength measurements were carried out in accordance with relevant standard of TS EN 1015-11 [17].

Results of compressive strength were altogether presented in Table 4 with fly ash replacement ratio, waterbinder ratio and curing times. One day compressive strengths of mortar containing fly ash were found to be lower than that of their control Portland cement mortar compressive strength. They reduced more with the increase in fly ash replacement ratio in mortar. Similar findings were observed for three, seven and twenty eight days compressive strength of mortar containing fly ash as obtained for one day compressive strength. After completion of three months curing time, mortar made with $10 \%$ fly ash replacement developed equivalent compressive strength to control Portland cement mortar strength. However, compressive strength of mortar containing 30\% fly ash significantly approached to strength of its control mixture. Moreover, after three months curing time, while compressive strength of mortar containing $10 \%$ fly ash exceeded strength of its counterpart control mortar, mortar made with $30 \%$ fly ash developed comparable and equal compressive strength to strength of control mortar mixture. When fly ash replacement ratio became 50\%, mortar made with gained compressive strength in the order of 40-50 MPa, while control Portland cement mortar achieved 55-70 MPa compressive strength. For 70\% fly ash replacement ratio in mortar, compressive strength development was in the order of 30-35 MPa, which was about $50 \%$ of control mortar mixture strength. Pozzolanic reaction contributes favourably to compressive strength of fly ash containing mortar in long term [10, 18, 19].

Increasing water-binder ratio caused a decrease in compressive strength of mortar regardless of containing fly ash. This is found to be valid for each curing time. This finding is in agreement with published literature [20].

Table 4. Compressive strength of all concrete produced (MPa)

\begin{tabular}{|l|l|l|l|l|l|l|l|}
\hline R. ratio(\%) & w/b (\%) & $1 \mathrm{~d}$ & $3 \mathrm{~d}$ & $7 \mathrm{~d}$ & $28 \mathrm{~d}$ & $3 \mathrm{~m}$ & $6 \mathrm{~m}$ \\
\hline 0 & 50 & 16,28 & 31,82 & 39,68 & 49,30 & 53,53 & 56,78 \\
\hline 0 & 45 & 20,90 & 36,11 & 45,12 & 50,08 & 58,60 & 59,75 \\
\hline 0 & 40 & 27,09 & 39,40 & 52,60 & 61,16 & 67,61 & 69,75 \\
\hline 10 & 50 & 13,75 & 26,43 & 34,69 & 45,38 & 53,81 & 60,56 \\
\hline 10 & 45 & 17,58 & 32,68 & 41,40 & 49,71 & 56,59 & 66,96 \\
\hline 10 & 40 & 19,54 & 38,50 & 46,03 & 54,48 & 63,63 & 71,90 \\
\hline 30 & 50 & 7,03 & 16,67 & 25,72 & 35,40 & 50,61 & 55,03 \\
\hline 30 & 45 & 9,95 & 23,67 & 29,99 & 42,80 & 54,24 & 60,39 \\
\hline 30 & 40 & 12,32 & 25,95 & 34,16 & 49,82 & 60,91 & 68,48 \\
\hline 50 & 50 & 3,92 & 11,11 & 15,45 & 24,49 & 33,63 & 43,64 \\
\hline 50 & 45 & 5,91 & 14,18 & 19,91 & 29,26 & 43,61 & 49,70 \\
\hline 50 & 40 & 7,64 & 17,14 & 24,12 & 35,15 & 48,55 & 53,75 \\
\hline 70 & 50 & 1,88 & 4,78 & 6,71 & 11,65 & 17,60 & 29,56 \\
\hline 70 & 45 & 2,04 & 6,39 & 8,79 & 14,27 & 20,67 & 33,62 \\
\hline 70 & 40 & 3,15 & 7,91 & 10,21 & 17,59 & 26,85 & 35,32 \\
\hline
\end{tabular}

Compressive strengths of mortars given in Table 4 were normalized with 28 days strength of their control mortar mixture to compare and evaluate compressive strength development of mortar with respect to 28 days compressive strength of control mixture. Normalized compressive strengths of all mortars were presented in Table 5. A close observation of Table 5 indicated that 28 days normalized compressive strength development of mortar containing $10 \%$ fly ash were in the order of 0.89 and 0.99 meaning they were significantly approached to 28 days compressive strength of control mixture. Moreover, at the end of three months curing time, they were exceeded 28 days compressive strength of control mortar strength. However, three months compressive strength of mortar including $30 \%$ fly ash was found to be equal or higher than 
that of their 28 days strength of control mortar mixture. Six months compressive strength developments of mortar containing $10 \%$ and $30 \%$ fly ash were far more than that of 28 days strength gain of their control mortar mixtures. Compressive strength development of fly ash mortar made with $50 \%$ fly ash get significantly near to their control mortar mixture strength, which were in the order of $90 \%$ of their control mortar strength. This was in the order of $60-70 \%$ for mortar incorporating $70 \%$ fly ash as partial cement replacement, which should be noted and remembered that binder was consisting $30 \%$ of cement.

Table 5. Compressive strength of mortar with 28 days compressive strength of corresponding reference mortar (MPa)

\begin{tabular}{|l|l|l|l|l|l|l|l|}
\hline R.ratio(\%) & w/b $(\%)$ & $1 \mathrm{~d}$ & $3 \mathrm{~d}$ & $7 \mathrm{~d}$ & $28 \mathrm{~d}$ & $3 \mathrm{~m}$ & $6 \mathrm{~m}$ \\
\hline 0 & 50 & 0,33 & 0,65 & 0,80 & 1,00 & 1,09 & 1,15 \\
\hline 0 & 45 & 0,42 & 0,72 & 0,90 & 1,00 & 1,17 & 1,19 \\
\hline 0 & 40 & 0,44 & 0,64 & 0,86 & 1,00 & 1,11 & 1,14 \\
\hline 10 & 50 & 0,28 & 0,54 & 0,70 & 0,92 & 1,09 & 1,23 \\
\hline 10 & 45 & 0,35 & 0,65 & 0,83 & 0,99 & 1,13 & 1,34 \\
\hline 10 & 40 & 0,32 & 0,63 & 0,75 & 0,89 & 1,04 & 1,18 \\
\hline 30 & 50 & 0,14 & 0,34 & 0,52 & 0,72 & 1,03 & 1,12 \\
\hline 30 & 45 & 0,20 & 0,47 & 0,60 & 0,85 & 1,08 & 1,21 \\
\hline 30 & 40 & 0,20 & 0,42 & 0,56 & 0,81 & 1,00 & 1,12 \\
\hline 50 & 50 & 0,08 & 0,23 & 0,31 & 0,50 & 0,68 & 0,89 \\
\hline 50 & 45 & 0,12 & 0,28 & 0,40 & 0,58 & 0,87 & 0,99 \\
\hline 50 & 40 & 0,12 & 0,28 & 0,39 & 0,57 & 0,79 & 0,88 \\
\hline 70 & 50 & 0,04 & 0,10 & 0,14 & 0,24 & 0,36 & 0,60 \\
\hline 70 & 45 & 0,04 & 0,13 & 0,18 & 0,29 & 0,41 & 0,67 \\
\hline 70 & 40 & 0,05 & 0,13 & 0,17 & 0,29 & 0,44 & 0,58 \\
\hline
\end{tabular}

Compressive strength of each mortar mixtures given in Table 4 were normalized with their 28 days compressive strength to evaluate compressive strength development rate with respect to its 28 days compressive strength. Normalized compressive strength for each mortar mixtures were presented in Table 6. It is understood from the normalization of compressive strength (see Table 6) with their 28 days compressive strength that control Portland cement mortars developed quick compressive strength at early age, however, they developed slow compressive after 28 days and beyond. When one-day compressive strength was in question, control Portland cement mortars developed a compressive strength in the range of $40 \%$ of their 28 -days compressive strength. This result was in the range of $30 \%$ of their 28 -days compressive strength for fly ash mortar made with $10 \%$ replacement level, it was reduced to about $20 \%$ for mortar containing 30\% fly ash as part of binder amount. When replacement ratios of fly ash were $50 \%$ and $70 \%$, strength development rate with respect to their 28-day compressive strength were in the range of $20 \%$ and $15 \%$, respectively.

When three months strength development was evaluated in terms of normalization with their 28-day strength, control mortar mixtures developed 15\% higher compressive strength than that its 28-day compressive strength. They were in average 17\%, 20\%, 30\%, and 45\% higher than their 28-day compressive strength for fly ash mortar made with $10 \%, 30 \%, 50 \%$ and $70 \%$ fly ash replacement.

Observation made on six months compressive strength showed that control Portland cement mortar gained $20 \%$ higher compressive strength than that its 28-day compressive strength. Strength gaining rates were $30 \%, 40 \%, 70 \%$ and $100 \%$ and over, for fly ash mortar with replacement ratios of $10 \%, 30 \%, 50 \%$ and $70 \%$, respectively, at six months curing time with respect to their 28 -day compressive strength values. This excess increment rate in compressive strength was an indicator for pozzolanic reaction which takes place between amorphous silicon dioxide content of fly ash and portlandite (Calcium hydroxide) existed as a result of hydration of $\mathrm{C}_{2} \mathrm{~S}$ and $\mathrm{C}_{3} \mathrm{~S}$ known as main components of Portland cement in the presence of water. 
Table 6. Compressive strength of

mortar with its 28 days compressive strength $(\mathrm{MPa})$

\begin{tabular}{|l|l|l|l|l|l|l|l|}
\hline R.ratio(\%) & w/b $(\%)$ & $1 \mathrm{~d}$ & $3 \mathrm{~d}$ & $7 \mathrm{~d}$ & $28 \mathrm{~d}$ & $3 \mathrm{~m}$ & $6 \mathrm{~m}$ \\
\hline 0 & 50 & 0,33 & 0,65 & 0,80 & 1,00 & 1,09 & 1,15 \\
\hline 0 & 45 & 0,42 & 0,72 & 0,90 & 1,00 & 1,17 & 1,19 \\
\hline 0 & 40 & 0,44 & 0,64 & 0,86 & 1,00 & 1,11 & 1,14 \\
\hline 10 & 50 & 0,30 & 0,58 & 0,76 & 1,00 & 1,19 & 1,33 \\
\hline 10 & 45 & 0,35 & 0,66 & 0,83 & 1,00 & 1,14 & 1,35 \\
\hline 10 & 40 & 0,36 & 0,71 & 0,84 & 1,00 & 1,17 & 1,32 \\
\hline 30 & 50 & 0,20 & 0,47 & 0,73 & 1,00 & 1,43 & 1,55 \\
\hline 30 & 45 & 0,23 & 0,55 & 0,70 & 1,00 & 1,27 & 1,41 \\
\hline 30 & 40 & 0,25 & 0,52 & 0,69 & 1,00 & 1,22 & 1,37 \\
\hline 50 & 50 & 0,16 & 0,45 & 0,63 & 1,00 & 1,37 & 1,78 \\
\hline 50 & 45 & 0,20 & 0,48 & 0,68 & 1,00 & 1,49 & 1,70 \\
\hline 50 & 40 & 0,22 & 0,49 & 0,69 & 1,00 & 1,38 & 1,53 \\
\hline 70 & 50 & 0,16 & 0,41 & 0,58 & 1,00 & 1,51 & 2,54 \\
\hline 70 & 45 & 0,14 & 0,45 & 0,62 & 1,00 & 1,45 & 2,36 \\
\hline 70 & 40 & 0,18 & 0,45 & 0,58 & 1,00 & 1,53 & 2,01 \\
\hline
\end{tabular}

\subsubsection{Influence Of Fly Ash Replacement Ratio On Compressive Strength}

Mortar compressive strength development during curing time was presented in Figure 1, for mortar including fly ash and control Portland cement mortar mixtures; to evaluate the influence of fly ash replacement ratios on compressive strength of mortar. Compressive strength development of mortar made with 0.45 water-binder ratio was selected for presentation, since all water-binder showed similar behaviour. It can be seen from Figure 1 that fly ash containing mortar developed lower strength than control Portland cement mortar did at early age. However, strength development rate of control mortar mixtures reduces during increase in curing time, contrary to this, strength development rate of fly ash mortar increases in curing time. Fly ash mortar developed such compressive strength which is higher or comparable to control Portland cement mixtures at 90 -day curing age for $10 \%$ and $30 \%$ fly ash replacement ratios with cement. Other two fly ash mortar made with $50 \%$ and $70 \%$ replacement ratios, although, did not developed equivalent compressive strength to control mortar mixture, but has shown a noteworthy good performance with respect to control mortar mixture. When six months strength development was questioned, fly ash mortars developed higher compressive strength than that of control Portland cement mortar for $10 \%$ and $30 \%$ replacement ratio with cement. Other two fly ash mortar made with high volume of 50\% and 70\% replacement ratio continued developing compressive strength; however, compressive strength gained were remained behind control Portland cement mortar. Nevertheless, the difference between compressive strength of control mortar mixture and fly ash mortar mixtures were diminished due to pozzolanic reaction and packing effect of unreacted fly ash particles [18, 19, 20,21].

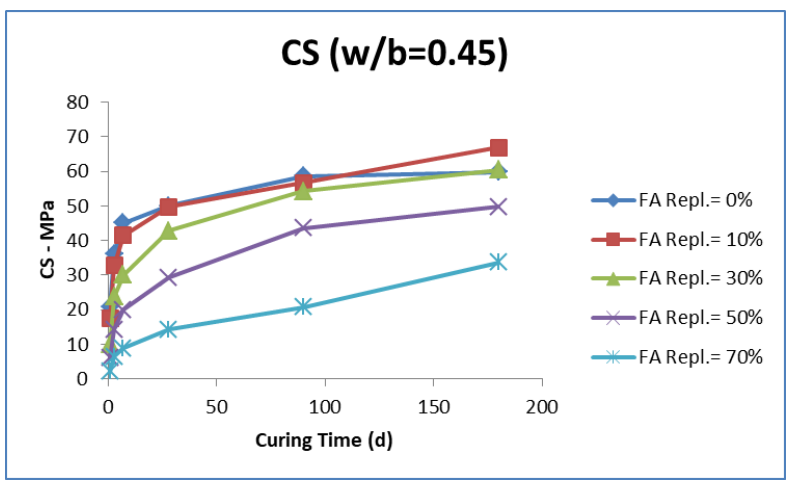

Figure 1. Compressive strength development of mortar 


\subsubsection{Influence Of Water-Binder Ratio On Compressive Strength}

During curing time, compressive strength developments of fly ash mortar containing 50\% fly ash as cement replacement selected for presentation were shown in Figure 2, with their water-binder ratio. This enabled to evaluate the influence of water-binder ratio on compressive strength development of mortar. It was seen from Figure 2 that compressive strength reduced with increase in water-binder ratio. The highest waterbinder ratio, 0.50 , results with lowest compressive strength, while the highest compressive strength associated with lowest water-binder ratio, 040. This finding is found to be valid for each curing time and other fly ash replacement ratio including control Portland cement mortar. This finding supports the relevant published literature [20].

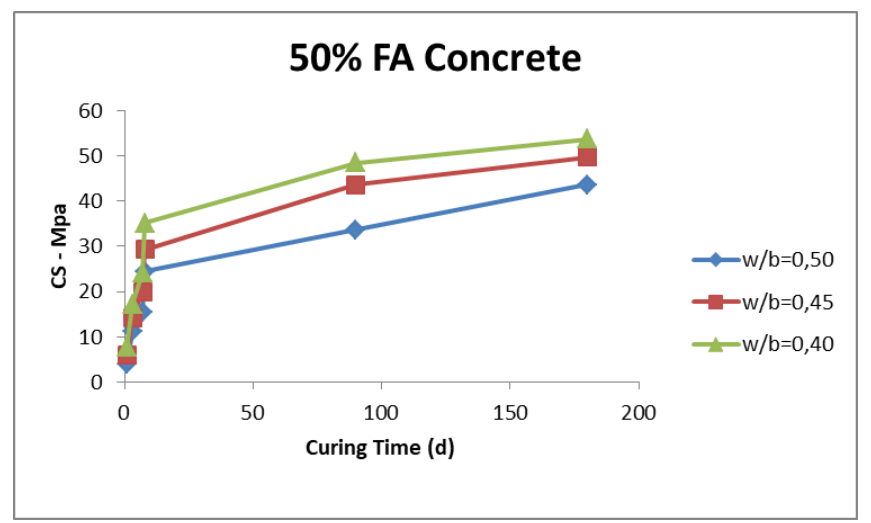

Figure 2. Compressive strength of mortar containing 50\% fly ash

\subsection{Flexural Strength Results}

Flexural strengths, measured in accordance with TS EN 1015-11 [17], were introduced in Table 7 for all mortar produced in the study. Flexural strength of control Portland cement mortar can be seen from Table 7 that they were in the range of $7 \mathrm{MPa}$ at one day curing age. Fly ash replacement in mortar results with a decrease in flexural strength at one day age. Increase in replacement ratio of fly ash caused further reduction in flexural strength at one day. Flexural strength values reduced to 2-3 MPa range for mortar containing high amount $70 \%$ replacement ratio of fly ash. Similar finding were observed at three and seven days flexural strength gaining, however, strength difference between control mortar mixture and fly ash mortar mixtures were significantly reduced particularly for mortar containing $10 \%$ and $30 \%$ fly ash. This strength difference was diminished and became equivalent to each other at 28 days curing age. Furthermore, at three months of curing age, fly ash concrete with 50\% replacement ratio gained flexural strength which was comparable to control mortar mixture. At the end of six months curing time, mortar containing 50\% fly ash gained equivalent flexural strength with control mortar mixtures. Mortar containing $70 \%$ fly ash developed comparable flexural strength to control mortar mixtures. This rapid strength gaining rate was attributed to pozzolanic reaction taking place between portlandite and amorphous silicon dioxide content of fly ash [1821]. 
Table 7. Flexural strength of all concrete produced (MPa)

\begin{tabular}{|l|l|l|l|l|l|l|l|}
\hline R.ratio(\%) & w/b $(\%)$ & $1 \mathrm{~d}$ & $3 \mathrm{~d}$ & $7 \mathrm{~d}$ & $28 \mathrm{~d}$ & $3 \mathrm{~m}$ & $6 \mathrm{~m}$ \\
\hline 0 & 50 & 7,20 & 8,98 & 10,30 & 11,13 & 11,69 & 12,10 \\
\hline 0 & 45 & 7,58 & 9,36 & 10,33 & 11,26 & 12,12 & 12,31 \\
\hline 0 & 40 & 7,82 & 9,51 & 10,79 & 12,04 & 12,54 & 12,61 \\
\hline 10 & 50 & 6,64 & 8,28 & 9,18 & 10,71 & 11,49 & 11,84 \\
\hline 10 & 45 & 6,83 & 9,18 & 9,91 & 11,10 & 11,60 & 12,19 \\
\hline 10 & 40 & 7,22 & 9,67 & 10,59 & 12,17 & 12,50 & 12,60 \\
\hline 30 & 50 & 4,98 & 6,86 & 7,98 & 9,80 & 11,16 & 12,32 \\
\hline 30 & 45 & 5,71 & 7,87 & 8,55 & 10,40 & 11,95 & 13,25 \\
\hline 30 & 40 & 5,90 & 8,06 & 9,33 & 10,67 & 12,07 & 13,37 \\
\hline 50 & 50 & 3,49 & 6,15 & 6,41 & 8,23 & 10,06 & 12,28 \\
\hline 50 & 45 & 4,76 & 5,37 & 6,90 & 8,97 & 10,79 & 12,68 \\
\hline 50 & 40 & 4,75 & 6,80 & 7,38 & 9,54 & 11,27 & 13,19 \\
\hline 70 & 50 & 2,14 & 4,02 & 4,97 & 5,93 & 7,79 & 10,05 \\
\hline 70 & 45 & 2,25 & 4,64 & 5,10 & 6,35 & 7,94 & 10,40 \\
\hline 70 & 40 & 2,74 & 4,96 & 5,61 & 6,88 & 8,96 & 10,62 \\
\hline
\end{tabular}

For a comparison purpose, mortar flexural strength development with respect to 28 days flexural strength of counterpart control mixture, all mortar strength presented in Table 7 was normalized with 28 days flexural strength of corresponding control Portland cement mortar. Normalized values of all flexural strength were given in Table 8. As it was observed in compressive strength case, control mortar mixtures developed quick flexural strength gain at early ages, however, in long term curing age strength gain was continued, but, slowed down. At the end of six months curing time, control mortar developed in the order of 5-9\% higher flexural strength than its 28 days strength. Similarly, mortar made with $10 \%$ inclusion of fly ash has shown parallel flexural strength development to control mortar mixture, for example it developed in the order of 5-8\% higher flexural strength than its corresponding 28 days strength of control mixture. When replacement ratio became $30 \%$ and $50 \%$, their strength gain was more than $10 \%$ of their control mortar mixture. The flexural strength gain with respect to 28 days control strength was $10 \%$ lower, for mortar containing $70 \%$ fly ash as partial replacement of cement at six months.

Table 8. Flexural strength of mortarwith 28 days flexural strength of corresponding reference mortar $(\mathrm{MPa})$

\begin{tabular}{|l|l|l|l|l|l|l|l|}
\hline R.ratio(\%) & w/b (\%) & $1 \mathrm{~d}$ & $3 \mathrm{~d}$ & $7 \mathrm{~d}$ & $28 \mathrm{~d}$ & $3 \mathrm{~m}$ & $6 \mathrm{~m}$ \\
\hline 0 & 50 & 0,65 & 0,81 & 0,92 & 1,00 & 1,05 & 1,09 \\
\hline 0 & 45 & 0,67 & 0,83 & 0,92 & 1,00 & 1,08 & 1,09 \\
\hline 0 & 40 & 0,65 & 0,79 & 0,90 & 1,00 & 1,04 & 1,05 \\
\hline 10 & 50 & 0,60 & 0,74 & 0,82 & 0,96 & 1,03 & 1,06 \\
\hline 10 & 45 & 0,61 & 0,82 & 0,88 & 0,99 & 1,03 & 1,08 \\
\hline 10 & 40 & 0,60 & 0,80 & 0,88 & 1,01 & 1,04 & 1,05 \\
\hline 30 & 50 & 0,45 & 0,62 & 0,72 & 0,88 & 1,00 & 1,11 \\
\hline 30 & 45 & 0,51 & 0,70 & 0,76 & 0,92 & 1,06 & 1,18 \\
\hline 30 & 40 & 0,49 & 0,67 & 0,78 & 0,89 & 1,00 & 1,11 \\
\hline 50 & 50 & 0,31 & 0,55 & 0,58 & 0,74 & 0,90 & 1,10 \\
\hline 50 & 45 & 0,42 & 0,48 & 0,61 & 0,80 & 0,96 & 1,13 \\
\hline 50 & 40 & 0,39 & 0,57 & 0,61 & 0,79 & 0,94 & 1,10 \\
\hline 70 & 50 & 0,19 & 0,36 & 0,45 & 0,53 & 0,70 & 0,90 \\
\hline 70 & 45 & 0,20 & 0,41 & 0,45 & 0,56 & 0,71 & 0,92 \\
\hline 70 & 40 & 0,23 & 0,41 & 0,47 & 0,57 & 0,74 & 0,88 \\
\hline
\end{tabular}

Flexural strengths of each mortar mixtures irrespective of curing ages were normalised with their 28 days flexural strength to evaluate strength gain rate with respect to their 28-days flexural strength. Normalised flexural strength values were provided in Table 9. As observed in compressive strength case, normalisation of flexural strength verified that control Portland cement mortars developed flexural strength gain rate was higher at early ages but lower in long term age with respect to their 28-day flexural strength. After six months curing time, control mortar mixtures made with cement gained 5\% - 9\% higher strength than their 28 day flexural strength. Six months flexural strength gaining was at average 10\%, 25\%, $40 \%$ and $65 \%$ higher with respect to their 28 days flexural strength for mortar containing $10 \%, 30 \%, 50 \%$ and $70 \%$ fly 
ash replacement, respectively. It can be observed that flexural strength gaining rates increases with increasing fly ash replacement ratio with respect to their 28 days flexural strength. Normalisation of flexural strength also showed that fly ash mortar flexural strength gaining rate was lower at early age but higher in long term curing age due to pozzolanic reaction of fly ash. While replacement ratio of fly ash increases, strength gaining rate decreases at early age, however, it increases in long term curing age.

Table 9. Flexural strength of mortar with its 28 days flexural strength (MPa)

\begin{tabular}{|l|l|l|l|l|l|l|l|}
\hline R.ratio(\%) & $\mathrm{w} / \mathrm{b}(\%)$ & $1 \mathrm{~d}$ & $3 \mathrm{~d}$ & $7 \mathrm{~d}$ & $28 \mathrm{~d}$ & $3 \mathrm{~m}$ & $6 \mathrm{~m}$ \\
\hline 0 & 50 & 0,65 & 0,81 & 0,92 & 1,00 & 1,05 & 1,09 \\
\hline 0 & 45 & 0,67 & 0,83 & 0,92 & 1,00 & 1,08 & 1,09 \\
\hline 0 & 40 & 0,65 & 0,79 & 0,90 & 1,00 & 1,04 & 1,05 \\
\hline 10 & 50 & 0,62 & 0,77 & 0,86 & 1,00 & 1,07 & 1,11 \\
\hline 10 & 45 & 0,62 & 0,83 & 0,89 & 1,00 & 1,05 & 1,10 \\
\hline 10 & 40 & 0,59 & 0,79 & 0,87 & 1,00 & 1,03 & 1,04 \\
\hline 30 & 50 & 0,51 & 0,70 & 0,81 & 1,00 & 1,14 & 1,26 \\
\hline 30 & 45 & 0,55 & 0,76 & 0,82 & 1,00 & 1,15 & 1,28 \\
\hline 30 & 40 & 0,55 & 0,76 & 0,87 & 1,00 & 1,13 & 1,25 \\
\hline 50 & 50 & 0,42 & 0,75 & 0,78 & 1,00 & 1,22 & 1,49 \\
\hline 50 & 45 & 0,53 & 0,60 & 0,77 & 1,00 & 1,20 & 1,41 \\
\hline 50 & 40 & 0,50 & 0,71 & 0,77 & 1,00 & 1,18 & 1,38 \\
\hline 70 & 50 & 0,36 & 0,68 & 0,84 & 1,00 & 1,31 & 1,70 \\
\hline 70 & 45 & 0,35 & 0,73 & 0,80 & 1,00 & 1,25 & 1,64 \\
\hline 70 & 40 & 0,40 & 0,72 & 0,82 & 1,00 & 1,30 & 1,54 \\
\hline
\end{tabular}

\subsubsection{Influence Of Fly Ash Replacement Ratio On Flexural Strength}

Flexural strength development of all fly mortar made with 0.45 water-binder ratio was presented for all curing age in Figure 3, to analyse the influence of fly ash replacement ratio on flexural strength of mortar. Figure 3 indicated that all fly ash containing mortar developed lower flexural strength than the control mortar did, at early curing ages. However, flexural strength development rate of control Portland cement mortar decreases in time, contrary to this; it increases for fly ash containing mortar mixtures. At three months curing time, fly ash mortar containing 10\%, 30\% and 50\% fly ash showed such flexural strength development nearing to 90-days flexural strength of control Portland cement mortar. Other fly ash mortar made with high amount of fly ash (70\% replacement ratio), did not develop equivalent flexural strength, but it showed a good performance with a progressive flexural strength development. When six months flexural strength was evaluated for fly ash containing mortar; all fly ash mortar mixtures developed equivalent or higher flexural strength than that of control Portland cement mortar, except mortar containing $70 \%$ fly ash as cement replacement. The mortar mixture made with $70 \%$ fly ash substitution continued to gain flexural strength, but the flexural strength development remained low compared to the control mixture. Nevertheless, flexural strength difference between mortar containing $70 \%$ fly ash and control mortar mixtures was fallen down in time $[18,19]$. Fly ash mortar made with 0.40 and 0.50 water-binder ratios exhibited similar results and findings. 


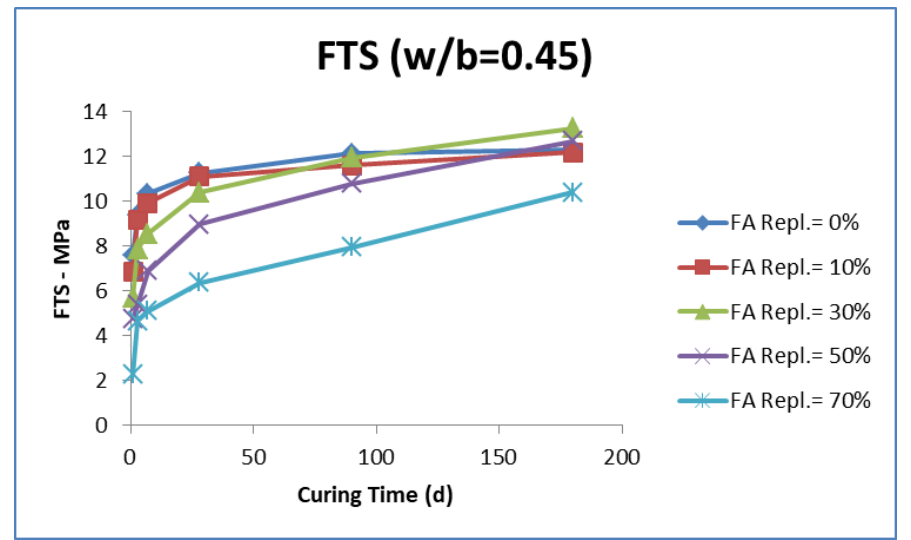

Figure 3. Flexural strength development of mortar

\subsubsection{Influence Of Water-Binder Ratio On Flexural Strength}

Flexural strength developments of fly ash concrete made with 50\% fly ash replacement and different water binder-ratio were presented in Figure 4 to evaluate the influence of water binder ratio on flexural strength development of fly ash mortar. Figure 4 shows that flexural strength of mortar presented reduces with an increase in water-binder ratio which is valid for each curing age. The highest flexural strength was obtained from lowest water-binder ratio, 0.40. Similarly, the lowest flexural strength was developed from highest water-binder ratio [20, 21]. This finding is found to be valid for each curing time and other fly ash replacement ratio including control Portland cement mortar.

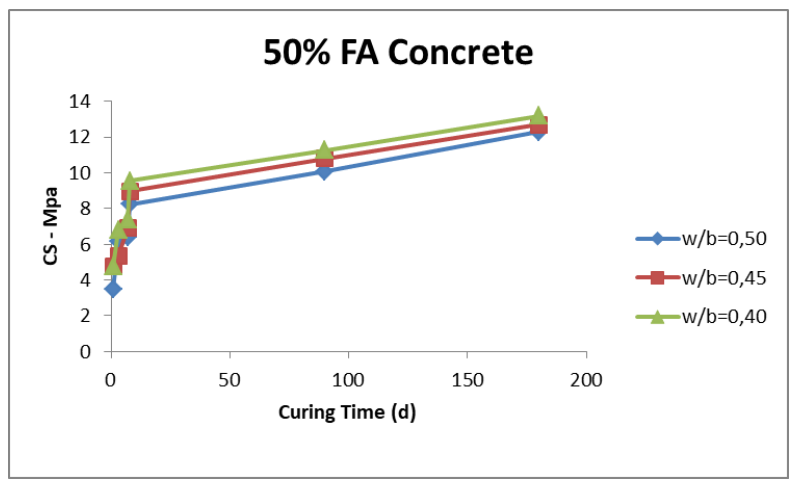

Figure 4. Flexural strength of mortar containing 50\% fly ash

\subsection{Relation Between Flexural Strength And Compressive Strength}

A relationship was established between flexural and compressive strength of all mortars produced. Relationship is presented in Figure 5, which shows a strong exponential relationship between compressive and flexural strength. Determination coefficient of relationship, $\mathrm{R}^{2}$, was $98 \%$. It is possible to predict flexural strength of mortar from compressive strength of mortar using the relationship established between flexural and compressive strength of mortar. 


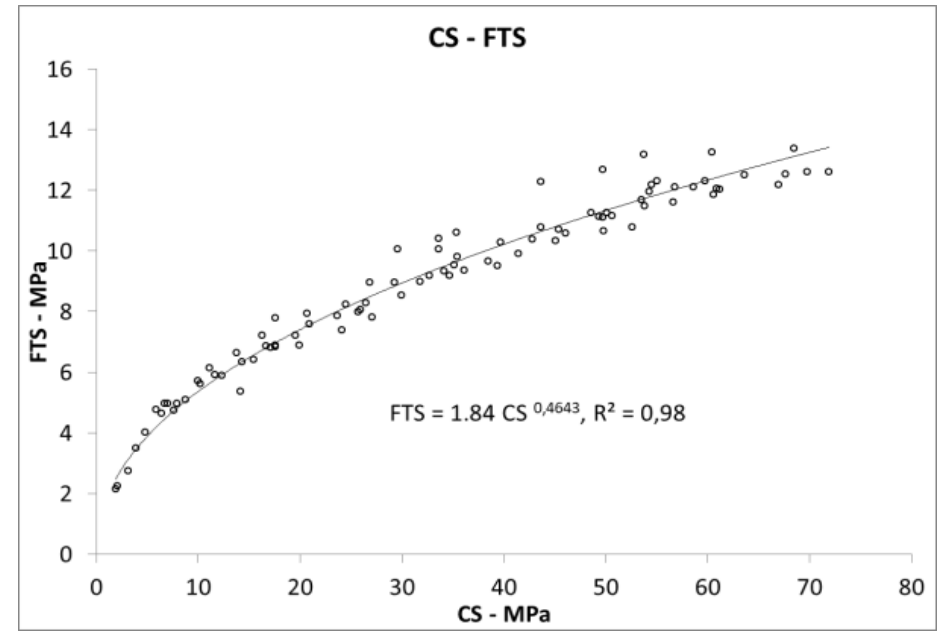

Figure 5. Relationship between compressive and flexural strength

\section{CONCLUSION}

1-While water-binder ratio increases, workability of fresh mortar increases; and flexural and compressive strength of mortar decrease regardless of containing fly ash.

2-Flexural and compressive strength is found to increase during curing time.

3-Workability of fresh concrete improved with the addition of fly ash in mortar.

4-Addition of fly ash in mortar reduces flexural and compressive strength with respect to control Portland cement mortar mixtures at early ages.

5-Increase in replacement ratio of fly ash in mortar results with higher rate of decrease in strength 6-At long term, strength difference between fly ash mortar and control Portland mortar diminishes in long term due to strength contribution of pozzolanic reaction of fly ash.

7-Current fly ash could be utilized as cement replacement in mortar mixture as an environment friendly product.

\section{REFERENCES}

[1] ASTM - C618-8a, (2009). ASTM - C618-8a, Standard Specification for Coal Fly Ash and Raw or Calcined Natural Pozzolan for Use in Concrete, ASTM International, USA .

[2] Hemalatha, T., Ramaswamy, T. A., (2017). A review on fly ash characteristics - towards promoting high volume utilization in developing sustainable concrete, Journal of Cleaner Production 147, 546559.

[3] Papadakis, V.G., S., Tsimas, S., (2002). Supplementary cementing materials in concrete: Part I: efficiency and design, Cement and Concrete Research, 32, 1525-1532.

[4] Papadakis, V.G., Antiohos, S. (2002). Tsimas, Supplementary cementing materials in concrete: Part II: A fundamental estimation of the efficiency factor, Cement and Concrete Research, 32, 1533-1538. 
[5] Rafieizonooz, M., Mirza, J., Salim, M.R., Hussin, M.W., \& Khankhaj, E., (2006). Investigation of coal bottom ash and fly ash in concrete as replacement for sand and cement, Construction and Building Materials, 116, 15-24.

[6] Maslehuddin, M., (1989). Effect of sand replacement on the early-age strength, gain and long-term corrosion-resisting characteristics of fly ash concrete, ACI Mater. J., 86, 58 - 62.

[7] Yao, Z.T., Ji, X.S., Sarker, P.K., Tang, J.H. Ge, L.Q., Xia, M.S., \& Y.Q. Xi, Y.Q., (2015). A comprehensive review on the applications of coal fly ash, Earth Sci Rev, 141, 105-121.

[8] Siddique, R., (2004). Performance characteristics of high-volume Class F fly ash concrete, Cement and Concrete Research 34, 487- 493.

[9] Ravina, D., P.K. Mehta, P.K., (1986). Properties of fresh concrete containing large, amounts of fly ash, Cement and Concrete Research, 16, 227-238.

[10] Chindaprasirt, P., Jaturapitakkul, C., \& Sinsiri, T., (2005). Effect of fly ash fineness on compressive strength and pore size of blended cement paste, Cement Concr Compos, 27, 425-428.

[11] Ali, M.B., Saidur, R., \& Hossain, M.S., (2011). A review on emission analysis in cement industries, Renewable Sustainable Energy Rev., 15, 2252-2261.

[12]Guo, X., H. Shi, H., \& Dick, W.A., (2010). Compressive strength and microstructural characteristics of class C fly ash geopolymer, Cement Concr. Compos., 32, 142-147.

[13] EPA, (2008). EPA, Study on Increasing the Usage of Recovered Mineral Components in Federally Funded Projects Involving Procurement of Cement or Concrete, Environmental Protection Agency.

[14] Wardhono, A., Law, D.W., \& Strano, A., (2015). The Strength of Alkali-activated Slag/fly Ash Mortar Blends at Ambient Temperature, Procedia Engineering, 125, 650-656.

[15] TS EN 196-1, (2002). Method of Testing Cement, Part 1: Determination of Strength, TSE, , Ankara, Turkey.

[16] ASTM C230, (2008). Standard Specification for Flow Table for Use in Tests of Hydraulic Cement, ASTM International, 100 Barr Harbour Drive, PO Box C700, West Conshohocken, PA 194282959, United States.

[17]TS EN 1015-11, (2000). Mortar Testing Method, Part 11: Measurement of Compressive and Flexural Tensile Strength of Mortar, TSE, Ankara, Turkey.

[18] Ahmaruzzaman, M., (2010). A review on the utilization of fly ash, Prog Energy Combust Sci, 36, 327-363.

[19] Gopalan, M.K., (1993). Nucleation and pozzolanic factors in strength development of class F fly ash concrete, ACI Mater. J., 90, 117-121. 
[20] Aïtcin, P.C., Flatt, R.J., (2006). Science and Technology of Concrete Admixtures, Woodhead Publishing Series in Civil and Structural Engineering: Number 59, ISBN: 978-0-08-100693-1, Woodhead Publishing, Elsevier.

[21]Isaia, G.C., Gastaldini, A.L.G., \& Moraes, R., (2003). Physical and pozzolanic action of mineral additions on the mechanical strength of high-performance concrete, Cem. Concr. Compos., 25, 6976. 